\title{
A novel form of recessive limb girdle muscular dystrophy with mental retardation and abnormal expression of $\alpha$-dystroglycan
}

\author{
Pervin Dinçer ${ }^{\mathrm{a}}$, Burcu Balc1 ${ }^{\mathrm{a}}$, Yeliz Yuva ${ }^{\mathrm{a}, \mathrm{b}}$, Beril Talim ${ }^{\mathrm{c}}$, Martin Brockington $^{\mathrm{b}}$, Deniz Dinçel ${ }^{\mathrm{d}}$, \\ Silvia Torelli ${ }^{\mathrm{b}}$, Sue Brown ${ }^{\mathrm{b}}$, Gülsev Kale ${ }^{\mathrm{c}}$, Göknur Haliloğlu ${ }^{\mathrm{e}}$, Filiz Özbas Gerçeker ${ }^{\mathrm{f}}$, Rengül \\ Çetin Atalay ${ }^{\mathrm{d}}$, Cengiz Yakıcıer ${ }^{\mathrm{d}}$, Cheryl Longman ${ }^{\mathrm{b}}$, Francesco Muntoni ${ }^{\mathrm{b}}$, Haluk Topaloğlu ${ }^{\mathrm{e}, *}$

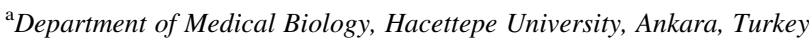 \\ ${ }^{\mathrm{b}}$ Dubowitz, Neuromuscular Centre, Department of Pediatrics, Faculty of Medicine, Imperial College, Hammersmith Campus, London, UK \\ ${ }^{\mathrm{c}}$ Department of Pediatric Pathology, Hacettepe University, Ankara, Turkey \\ ${ }^{\mathrm{d} D e p a r t m e n t ~ o f ~ M o l e c u l a r ~ B i o l o g y ~ a n d ~ G e n e t i c s, ~ F a c u l t y ~ o f ~ S c i e n c e, ~ B i l k e n t ~ U n i v e r s i t y, ~ A n k a r a, ~ T u r k e y ~}$ \\ ${ }^{\mathrm{e}}$ Department of Pediatric Neurology, Faculty of Medicine, Hacettepe University, Sihhlye, 06100 Ankara, Turkey \\ ${ }^{\mathrm{f}}$ TÜBITAK DNA/Cell Bank and Gene Research Laboratory, Hacettepe University, Ankara, Turkey
}

Received 15 April 2003; received in revised form 16 June 2003; accepted 7 July 2003

\begin{abstract}
The limb girdle muscular dystrophies are a heterogeneous group of conditions characterized by proximal muscle weakness and disease onset ranging from infancy to adulthood. We report here eight patients from seven unrelated families affected by a novel and relatively mild form of autosomal recessive limb girdle muscular dystrophy (LGMD2) with onset in the first decade of life and characterized by severe mental retardation but normal brain imaging. Immunocytochemical studies revealed a significant selective reduction of $\alpha$-dystroglycan expression in the muscle biopsies. Linkage analysis excluded known loci for both limb girdle muscular dystrophy and congenital muscular dystrophies in the consanguineous families. We consider that this represents a novel form of muscular dystrophy with associated brain involvement. The biochemical studies suggest that it may belong to the growing number of muscular dystrophies with abnormal expression of $\alpha$-dystroglycan.

(C) 2003 Published by Elsevier B.V.
\end{abstract}

Keywords: LGMD2; Autosomal recessive limb girdle muscular dystrophy; Mental retardation; Microcephaly; $\alpha$-Dystroglycan

\section{Introduction}

Autosomal recessive limb girdle muscular dystrophy (LGMD2) is a heterogeneous group of myopathies characterized by progressive muscle weakness involving the proximal muscles of the shoulder and pelvic girdles and a variable progression with symptoms ranging from Duchenne-like to milder, later onset forms $[1,2]$. Ten LGMD2 loci and their respective genes have been identified: these include the enzymatic protein calpain 3 (CAPN3, responsible for LGMD2A, on 15q) [3], the sarcolemmal proteins dysferlin (LGMD2B, 2p) [4,5], $\alpha, \beta, \gamma$ and $\delta$ sarcoglycans (LGMD2D, 2E, 2C and 2F) [6-10] and LGMD2G mapping to $17 \mathrm{q} 11-\mathrm{q} 12$, the gene product of which is the sarcomeric

\footnotetext{
* Corresponding author. Tel.: +90-312-440-2033; fax: +90-312-4402034.

E-mail address: htopalog@hacettepe.edu.tr (H. Topaloğlu).
}

protein telethonin [11]. The genes for LGMD2H, LGMD2I and LGMD2J have recently been identified: LGMD2H is due to mutations in the tripartite-motif containing gene 32 (TRIM32), an ubiquitin ligase putatively involved in proteasome degradation [12] whilst the gene encoding the giant sarcomeric protein titin is mutated in LGMD2J [13].

The gene responsible for LGMD2I is unusual in that it encodes a putative glycosyltransferase, the fukutin related protein gene (FKRP). This gene has been found to be mutated in patients with phenotypes ranging from severe congenital muscular dystrophy (MDC1C) to a mild form of limb girdle muscular dystrophy $[14,15]$. Abnormal $\alpha$-dystroglycan expression is a feature of both MDC1C and LGMD2I, suggesting that $F K R P$ might be involved in $\alpha$-dystroglycan processing.

Dystroglycan is a central component of the dystrophinglycoprotein complex (DGC), which links dystrophin to 
the extracellular matrix. In skeletal muscle it consists of a $156 \mathrm{kDa}$ extracellular subunit ( $\alpha$-dystroglycan) and a 43 $\mathrm{kDa}$ transmembrane subunit ( $\beta$-dystroglycan) [16].

$\alpha$-Dystroglycan is a heavily glycosylated protein expressed in a wide variety of cell types. In muscle it is a high-affinity receptor for several extracellular matrix molecules containing LG domains, including agrin [17], laminin $\alpha$ chains [18], perlecan [19] and biglycan [20], whilst in brain it also binds neurexin [21].

The interactions between $\alpha$-dystroglycan and many of its extracellular binding partners are mediated by its carbohydrate side chains. $\alpha$-dystroglycan contains both $N$-linked and $O$-linked carbohydrates. $N$-Linked glycosylation is less common but is required for the proper cell surface localization of both $\alpha$ - and $\beta$-dystroglycan [22]. $O$-Linked glycosylation is the predominant modification and responsible for the high affinity binding of $\alpha$-dystroglycan to its ligands [18].

To date, no disease has been found that is due to primary mutations in dystroglycan, although a mild form of muscular dystrophy associated with a secondary $\beta$-dystroglycan deficiency has been described [23]. In addition to LGMD2I, abnormal $\alpha$-dystroglycan expression has been documented in several forms of congenital muscular dystrophy (CMD), with and without central nervous system (CNS) involvement. These include Fukuyama CMD (FCMD) [24], MDC1C [15], muscle-eye-brain disease (MEB) [25] and Walker-Warburg syndrome (WWS) [26].

In the present study, we report seven families with identical clinical features, characterized by relatively mild and static proximal muscle weakness, mild muscle hypertrophy, elevated serum creatine kinase (CK), microcephaly and mental retardation but normal brain imaging. The expression of $\alpha$-dystroglycan was found to be reduced in their skeletal muscle biopsies. Linkage analysis excluded all the mapped forms of muscular dystrophies in consanguineous families, suggesting these patients represent a new variant of muscular dystrophy.

\section{Patients and methods}

\subsection{Patients}

Over the past decade, we have evaluated a large series of autosomal recessive LGMD families, the majority of which have been reported in two consecutive papers which combine clinical and genetic features $[27,28]$. Nine of the families studied did not map to any of the known LGMD loci and were referred to as 'unlinked'. Among these, there were six Turkish families sharing an almost identical phenotype who form the basis of the present study. More recently, a British family was seen at the Hammersmith Hospital (London, UK) with very similar clinical features. A summary of the clinical features of all families in this study are given in Table 1. Typically, all patients presented in the first decade of life with fatigability, difficulty in climbing stairs and in running. They acquired early motor milestones at a normal age, excluding a congenital muscular dystrophy. All were characterized by only mild muscle pseudohypertrophy and a slow disease evolution. All had mild to severe mental retardation, i.e. IQ levels being on average around 50-55. Serum CK was invariably grossly elevated (9-20 fold increase).

For illustrative purposes the case histories of two patients are presented below.

\subsubsection{Case 1}

This is a 22-year-old male coming from a first-degree consanguineous marriage who walked at 3 years. His early motor milestones were otherwise normal; symptoms started around 6 years of age with difficulty in gait. His intellectual

Table 1

Clinical characteristics

\begin{tabular}{|c|c|c|c|c|c|c|c|c|c|c|c|c|c|}
\hline & $\begin{array}{l}\text { Current } \\
\text { age/onset } \\
\text { (years) }\end{array}$ & Sex & $\begin{array}{l}\text { Consang- } \\
\text { uinity }\end{array}$ & $\begin{array}{l}\text { Family } \\
\text { history }\end{array}$ & $\begin{array}{l}\text { Age } \\
\text { walked } \\
\text { (years) }\end{array}$ & $\begin{array}{l}\text { Maximum } \\
\text { motor } \\
\text { capacity }\end{array}$ & Hypertrophy & $\begin{array}{l}\text { Joint } \\
\text { contractures }\end{array}$ & H.C. $\%$ & IQ & CK & CT/MRI & Evolution \\
\hline Case 1 & $22(6)$ & M & $(+)$ & $(+)$ & 3 & Walks alone & Calves & Elbow, Achilles & $3-10 p$ & 50 & $\times 9$ & $\mathrm{~N}$ & Mild \\
\hline Case 2 & $16(3)$ & $\mathrm{F}$ & $(+)$ & $(-)$ & 3 & Walks alone & Calves & Achilles & $3-10 p$ & 55 & $\times 20$ & $\mathrm{~N}$ & Mild \\
\hline Case 3 & $6(2.5)$ & $\mathrm{F}$ & $(+)$ & $(-)$ & 3 & Walks alone & $\begin{array}{l}\text { Thigh, } \\
\text { calves }\end{array}$ & - & $10 \mathrm{p}$ & 65 & $\times 28$ & $\mathrm{~N}$ & Mild \\
\hline Case 4 & $10(1)$ & M & $(+)$ & $(-)$ & 3 & Walks alone & $(-)$ & $(-)$ & $3 p$ & 50 & & $\mathrm{~N}$ & Mild \\
\hline Case 5 & $9(3)$ & M & $(+)$ & $(-)$ & 3 & Walks alone & $(-)$ & $(-)$ & $10-25 p$ & 50 & $\times 40$ & $\mathrm{~N}$ & Mild \\
\hline Case 6 & $10(3)$ & M & $(-)$ & $(-)$ & 3 & Walks alone & $\begin{array}{l}\text { Thigh, calves, } \\
\text { upper arms }\end{array}$ & $(-)$ & $50 \mathrm{p}$ & 55 & $\times 25$ & $\mathrm{~N}$ & Mild \\
\hline Case $7^{\mathrm{a}}$ & $12(5)$ & M & $(+)$ & a & 1.5 & Walks alone & Thigh, calves & Achilles & $3 p$ & 76 & $\times 22$ & $\mathrm{~N}$ & Mild \\
\hline Case $8^{\mathrm{a}}$ & $15(4)$ & $\mathrm{F}$ & $(+)$ & a & 2 & Walks alone & $\begin{array}{l}\text { Thigh, calves, } \\
\text { hamstring, } \\
\text { upper arm }\end{array}$ & Achilles & $3 p$ & 57 & $\times 24$ & $\mathrm{~N}$ & Mild \\
\hline
\end{tabular}

H.C., head circumference; CK, creatine kinase; CT/MRI, computed tomography/magnetic resonance imaging; p, centile; N, normal.

a Siblings. 
milestones were, however, clearly delayed; he said his first few words at 3 years, but later on failed to learn to read and write. When examined at 11 years of age, Gowers sign was negative, he raised himself from the floor in less than $3 \mathrm{~s}$ and his proximal muscle strength was MRC $4^{+} / 5$. Serum CK at the time was $2327 \mathrm{U} / \mathrm{l}$ (normal < 190). At the age of 16 years, his proximal weakness had increased and he now had a positive Gowers manoeuvre in 4-5 s. A repeated CK was 1931 U/l. When re-examined at 22 years, his head circumference was $53 \mathrm{~cm}$ (3-10 centile); muscle weakness had remained virtually static, with muscle power MRC 4/5 proximally. His calves were mildly enlarged. He had increased lumbar lordosis with mild elbow and ankle contractures (Fig. 1). Gowers sign was positive with 7-8 s. He could walk for long distances without significant difficulties. There was no prominent facial weakness or scapular winging. With regard to his intellectual function, he was unable to count money or take a bus ride in the city alone, and formal testing disclosed an IQ of 55. Out of nine siblings, his 7-year younger brother is similarly affected.

\subsubsection{Case 2}

This is a 16-year-old girl coming from a second-degree cousins marriage with no other relevant family history. The onset was around 3 years of age, shortly after she started to walk. Her initial difficulties were an unsteady gait and difficulties climbing stairs. This later progressed to a waddling gait with a Gowers manoeuvre of $10 \mathrm{~s}$ at the age of 14 years. At the last visit at the age of 16 her head circumference was $53 \mathrm{~cm} \mathrm{(3-10} \mathrm{centile).} \mathrm{Currently,} \mathrm{she} \mathrm{has}$ mild enlargement of the calves and ankle contractures as well as increased lumbar lordosis. There is no facial weakness nor muscle atrophy. Her proximal muscle strength is MRC $3^{+} / 5$. She is independently ambulant, but only for short distances, 25-30 m. Her intellectual development was

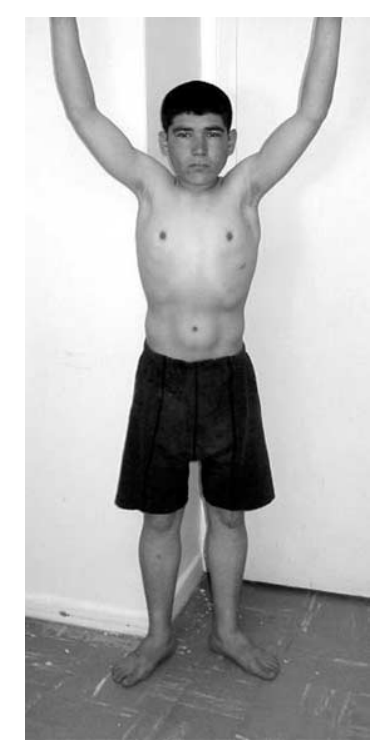

Fig. 1. Case 1: can easily raise arms above head, mild pseudohypertrophy, IQ55. slow: she said her first few words at 7 years and now, aged 16 , she only uses two-word sentences. Her IQ is 50 . She is also unable to count money and perform independent activities. The CK at the age of 15 is $4133 \mathrm{U} / \mathrm{l}$ (normal $<209$ ). Her cranial magnetic resonance image (MRI) is normal. This case represents the most severely affected patient in our series.

\subsection{Genotyping}

Genomic DNA was extracted from whole blood by standard methods after obtaining informed consent. Highly polymorphic markers of chromosomes $2 \mathrm{p} 13-\mathrm{p} 16,4 \mathrm{q} 12$, $5 q 33-q 34,13 q 12,15 q 15.1-q 15.3,17 q 12-q 21.33$ were analysed for these six LGMD2 families in the previous study [28]. The markers used in this study were the following: LGMD2G (D17S1851, D17S1818, D17S1814); LGMD2H (D9S1811, D9S195, D9S1872, D9S1850); LGMD2I (MDC1C) (D19S412, D19S606, D19S596, D19S879). In addition, the following loci responsible for the following CMD syndromes were excluded: LAMA2 with markers D6S407, D6S1705, and D6S1620 [29-31]; RSMD1 with markers D1S458, D1S2674, D1S234, D1S2885, and D1S511 [32]; MEB with markers D1S211, D1S2677, D1S427, D1S2652, and D1S200 [33]; FCMD with markers D9S2105 and D9S2107 [34]; and MDC1B (D1S213, D1S2833, D1S2709, D1S459 [14]). In addition, the FKRP gene was sequenced in all families as already described [15].

(CA)n microsatellite markers were provided from the Genethon human genetic linkage map [35]. Haplotypes were constructed by minimizing the number of recombination events. Linkage was ascertained by homozygosity by descent.

\subsection{Immunocytochemistry}

Unfixed frozen $8-\mu \mathrm{m}$ sections were incubated with monoclonal antibodies to $\beta$-spectrin, dystrophin, $\alpha-\beta-$ $\gamma$-, and $\delta$-sarcoglycan, laminin $\alpha 2, \beta$-dystroglycan (all available from Novocastra Laboratories), and $\alpha$-dystroglycan (VIA4-1, Upstate Biotechnology) for $1 \mathrm{~h}$. Then, a biotin-conjugated secondary antibody (Amersham) and Texas Red-conjugated streptavidin (Amersham) were applied to all sections for 45 and $30 \mathrm{~min}$, respectively. All dilutions and washings were made in phosphate buffered saline. Sections were examined by a Leica Aristoplan microscope.

\subsection{Immunoblotting}

Immunoblot analyses were performed in two patients (cases 1 and 2) as described by Piccolo et al. [36]. The primary antibodies used were against, respectively, dystrophin (DYS1 and DYS2, Novocastra 1:100), $\alpha-, \beta-, \gamma-$ and $\delta$-sarcoglycan (Novocastra 1:50). 


\subsection{Immunoprecipitation}

Co-immunoprecipitation was carried out using a previously reported protocol by Kessler et al. [37] with the following modifications. Muscle tissue $\left(0.25 \mathrm{~cm}^{3}\right)$ was homogenized by Dounce homogenizer in $100 \mu \mathrm{l}$ RIPA (1\% NP-40,1\% sodium deoxycholate, 0.1\% SDS, $150 \mathrm{mM} \mathrm{NaCl}, 100 \mathrm{mM}$ sodium phosphate, $\mathrm{pH}$ 7.2) containing $1 \times$ protease cocktail (Roche Biochemicals) and centrifuged. The supernatant was retained, and incubated overnight at $4{ }^{\circ} \mathrm{C}$ with $25 \mu \mathrm{l}$ protein-GSepharose (Pharmacia) coupled with antibodies specific to anti- $\alpha$-dystroglycan (polyclonal antibody, courtesy of Dr Stephan Kröger, 1:100) [38] antibodies. Subsequently, the beads were washed three times with RIPA, boiled in Laemmli buffer and applied into $10 \%$ sodium dodecyl sulphate-polyacrylamide gel electrophoresis. They were then transferred onto nitrocellulose membranes and blotted with anti- $\beta$-dystroglycan antibodies (Novocastra 1:250).

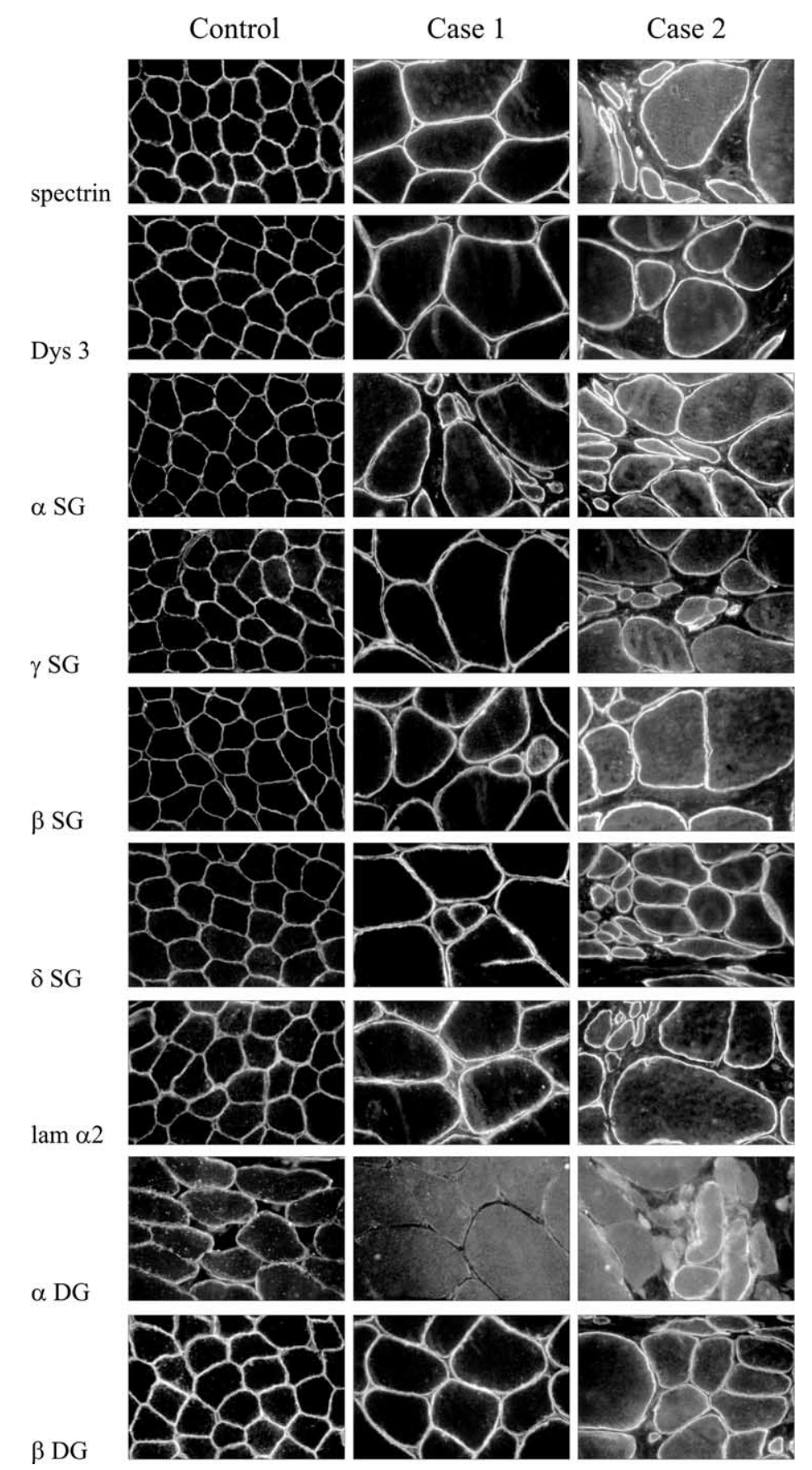

Fig. 2. Immunocytochemical analysis of dystrophin, sarcoglycans $(\alpha, \beta, \gamma$, and $\delta$ ), laminin $\alpha-2$, and dystroglycans ( $\alpha$-dystroglycan (VIA4-1 antibody) and $\beta$-dystroglycan) in cases 1 and 2 . Note significantly reduced labelling for only $\alpha$-dystroglycan. 


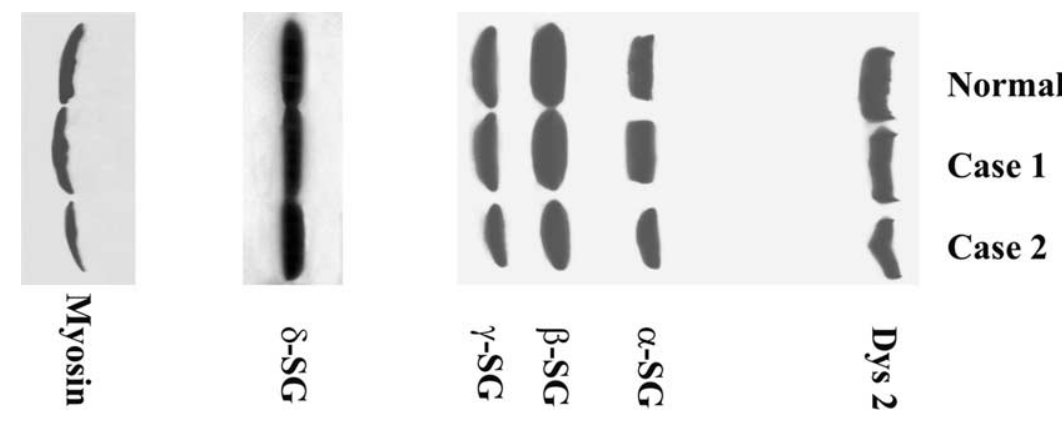

Fig. 3. Western blot analysis of dys $2, \alpha-, \beta-, \gamma$ - and $\delta$-sarcoglycans in cases 1 and 2.

\section{Results}

\subsection{Genotyping}

All families were haplotyped with microsatellite markers spanning the loci of autosomal recessive LGMD genes (LGMD2A, LGMD2B, LGMD2C, LGMD2D, LGMD2E, LGMD2F, LGMD2G, LGMD2H, LGMD2I) and five CMD forms (MDC1A, MDC1B, MDC1C, FCMD and MEB). No family showed haplotypes consistent with linkage to any of these loci.

\subsection{Immunocytochemistry and Immunoblotting}

The histological changes on muscle biopsies were compatible with muscular dystrophy. There was mild fibrosis with many regenerating and few necrotic fibres. Variation in fibre size was remarkable; many fibres were hypertrophic with multiple central nuclei and there were atrophic fibres most of which were type II. Some angular fibres were also present.

The expression of all proteins we regularly screen in the biopsies of patients with muscular dystrophy (dystrophin, laminin $\alpha 2, \alpha-, \beta-, \gamma$ - and $\delta$-sarcoglycans) were normal in all patients in whom muscle biopsy was available for immunofluorescence (cases 1, 2, 3, 5, 6, and 7) (Fig. 2: data shown for cases 1 and 2) and immunoblotting (cases 1 and 2) (Fig. 3). With monoclonal VIA4-1 antibody directed towards a glycosylated epitope, significantly reduced labelling for $\alpha$-dystroglycan was observed in all biopsies examined (Figs. 2 and 4: data shown for cases 1, 2, and 7). The muscle biopsies of cases 2 and 7 were also labelled using the antibody to the core dystroglycan protein and showed a profound reduction in agreement with that seen with V1A4-1 (Fig. 4). $\beta$-Dystroglycan immunolabelling was within normal limits in all patients (Fig. 2: data shown for cases 1 and 2).

\subsection{Demonstration of $\alpha$ - and $\beta$-dystroglycan complex}

We tested the presence of $\alpha$ - and $\beta$-dystroglycan complex formation by co-immunoprecipitation in cases 1 and 2. Co-immunoprecipitation using anti- $\alpha$-dystroglycan and immunoblotting using anti- $\beta$-dystroglycan demonstrated that $\alpha$ - and $\beta$-dystroglycan were able to form a complex in both patients (Fig. 5).

\section{Discussion}

In this study we present a novel and unique LGMD phenotype. In addition to the classical features of LGMD, all patients invariably had mental retardation with microcephaly and normal brain imaging. All families but one were consanguineous. We propose to name this novel variant recessive limb girdle muscular dystrophy with
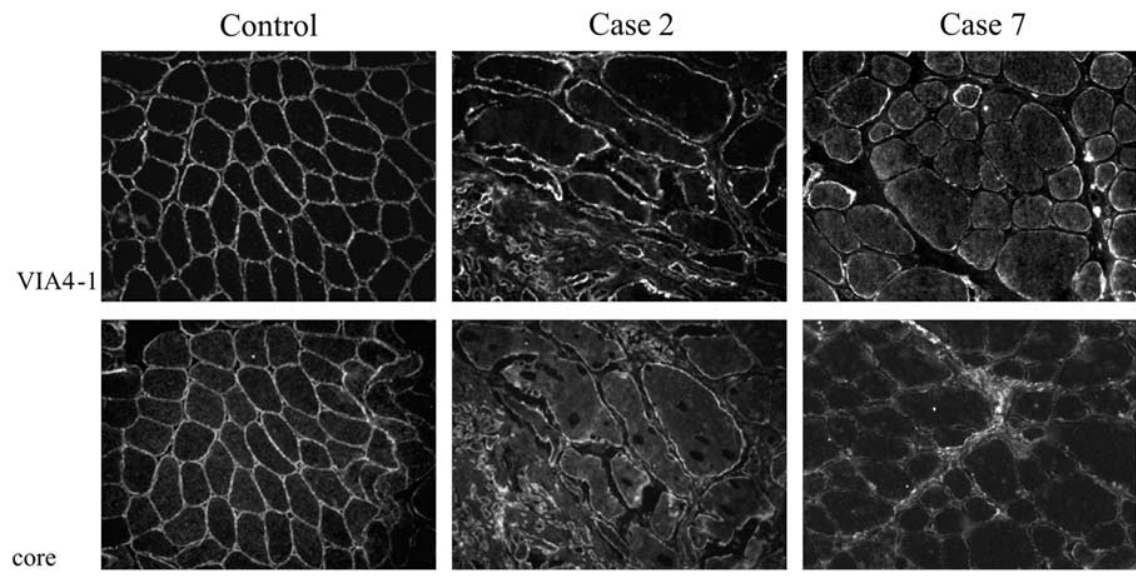

Fig. 4. Immunocytochemical analysis of $\alpha$-dystroglycan by using VIA4-1 and core antibodies in cases 2 and 7. 

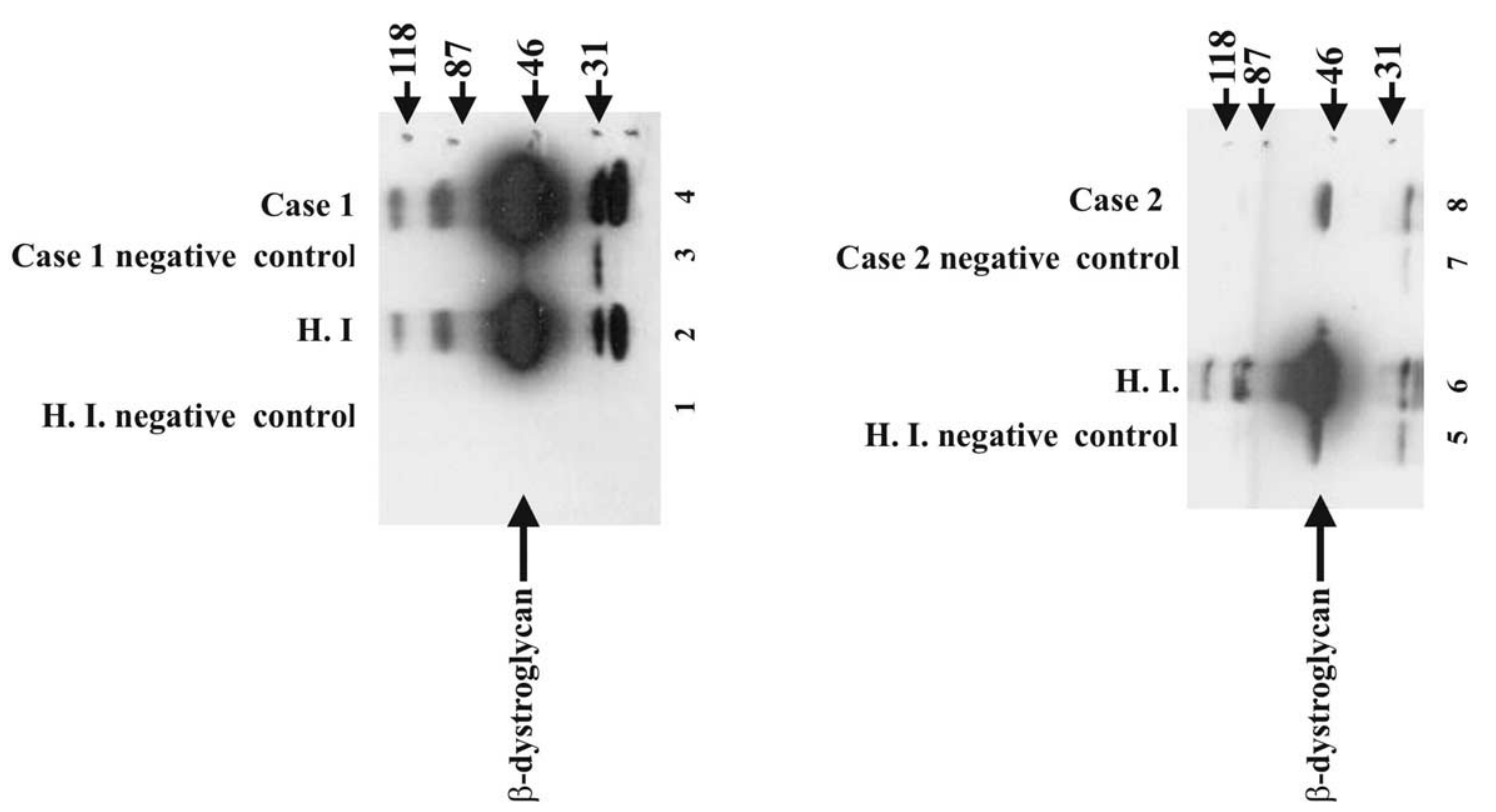

Fig. 5. Co-immunoprecipitation of $\beta$-dystroglycan with $\alpha$-dystroglycan. $\beta$-Dystroglycan protein is co-immunoprecipitated with $\alpha$-dystroglycan by using form of $\alpha$-dystroglycan. $\beta$-Dystroglycan protein is visualized by immunoblotting using anti- $\beta$-dystroglycan antibodies. Healthy individuals' (HI) skeletal muscle tissue is used as positive controls (lanes $1,2,5,6$ ). No $\alpha$-dystroglycan antibody added to negative controls during co-immunoprecipitation (lanes $1,3,5,7$ ).

mental retardation. From a skeletal muscle point of view, the course is mild despite onset in the first decade of life in all cases and different degrees of reduction in $\alpha$-dystroglycan expression. All patients remain ambulant, the eldest being 22 years old. Standard cranial MRIs failed to show any evidence of central nervous system malformations or white matter changes. In addition, none of the patients had epilepsy, a common complication of neuronal migration disorders. To our knowledge, such a phenotype has not been previously described. In addition, with the exception of LGMD2I, the abnormal expression of $\alpha$-dystroglycan has not been reported in other forms of LGMD, further suggesting that this form represents a new clinical entity. $\alpha$-dystroglycan expression was significantly reduced in skeletal muscle, as judged by using an antibody directed towards a glycosylated epitope and in two patients using the antibody to the core $\alpha$-dystroglycan protein. Similar findings have been observed in patients with MDC1C, due to mutations in the FKRP gene (Brown et al., submitted for publication). However, mutations in the FKRP gene were excluded in all families. Our experiments also suggest that the residual $\alpha$-dystroglycan expression is still capable of binding to $\beta$-dystroglycan. This is important as $\alpha$-dystroglycan associates with Grb2 (growth factor receptor bound 2), a protein that participates in signal transduction pathways involving receptor tyrosine kinases [39].

Dystroglycan is a widely expressed and heavily glycosylated protein, but its glycosylation pattern varies in a tissue-specific and developmental pattern. Recently a new pathomechanism responsible for several forms of CMD and for LGMD2I was reported following the identification of mutations in genes with putative or definite glycosyltransferase activity [40]. This includes mutations in fukutin and the fukutin-related-protein gene (FKRP), which are mutated in FCMD and MDC1C, respectively [14,24,41]. While in FCMD there are invariably associated structural brain abnormalities, mutations in the FKRP gene do not usually affect the brain. Allelic mutations in the FKRP gene were recently shown also to be responsible for LGMD2I, a very common form of LGMD in the Caucasian population [15]. Two other CMD forms have recently been demonstrated to be due to mutations in genes encoding glycosyltransferases, MEB disease and Walker-Warburg syndrome [25,26]. Both these CMD variants result in CNS defects in the form of neuronal migration disorders. These findings unequivocally indicate that altered glycosylation is a common underlying cause of muscular dystrophies. The abnormal expression of $\alpha$-dystroglycan suggests that this protein is abnormally processed in this novel form, and that its abnormal function might account for both the muscle weakness and the mental retardation.

Dystroglycan is also expressed abundantly in neurons, astrocytes, and in the glial-vascular interface, suggesting a role in maintenance of the blood-brain barrier [42]. This was further confirmed by the recent finding by Moore et al. [43] who generated a mouse with a brain-specific deletion of dystroglycan. This resulted in discontinuities of the pial surface basal lamina (glia limitans) and brain malformation including disarray of cerebral cortical layering, fusion of cerebral hemispheres and cerebellar folia, and aberrant migration of granule cells. This is similar to the abnormalities demonstrated in the brain of patients with MEB disease and FCMD. In addition, Michele et al. [21] recently reported that the abnormal processing of $\alpha$-dystroglycan in FCMD and MEB disease abolishes its ability to bind laminin, agrin, and neurexin. Both agrin and neurexin are 
neuronal dystroglycan receptors in brain, and it has been suggested that neurexins' tightly regulated interaction could mediate cell adhesion between brain cells [44]. We do not have sufficient muscle available to study the binding properties of the $\alpha$-dystroglycan produced by these patients to neurexin; we could, however, speculate that this interaction could be partially affected (and not totally abolished) in this form of limb girdle muscular dystrophy with mental retardation.

This form of limb girdle muscular dystrophy is likely to represent another form of muscular dystrophy secondary to abnormal glycosylation of $\alpha$-dystroglycan, adding to the growing number of muscular dystrophies secondary to mutations in genes encoding for putative glycosyltransferases [40].

\section{Acknowledgements}

We are thankful to patients and their families for their participation in this study. We received inspirational help from Professor J.C. Kaplan, Paris, Dr J. Beckmann, Israel and Professor J.A. Urtizberea, Paris. We wish to thank Stephan Kroger, Germany for the gift of the sheep polyclonal antibodies against $\alpha$-dystroglycan. We would like to thank to the following Institutions for their financial help: AFM, France; International Atomic Energy Agency (IAEA); Muscular Dystrophy Campaign of Great Britain and Northern Ireland (F.M.), the European Community (Myo-Cluster: GENRE grant QLG1 CT 1999 00870) (F.M.). We appreciate the help of the TÜBITAK DNA/Cell Bank and Gene Research Laboratory, Hacettepe University, Ankara, Turkey. A British Council grant was awarded to Y.Y.

\section{References}

[1] Walton JN, Nattrass FJ. On the classification, natural history and treatment of the myopathies. Brain 1954;77:169-231.

[2] Bushby KMD, Beckmann JS. Report of the 30th and 31st ENMC international workshop-the limb girdle muscular dystrophies, and proposal for a new nomenclature. Neuromuscul Disord 1995;5: 337-44.

[3] Richard I, Broux O, Allamand V, et al. Mutations in the proteolytic enzyme calpain 3 cause limb girdle muscular dystrophy type 2A. Cell 1995;81:27-40.

[4] Bashir R, Britton S, Strachan T, et al. A gene related to Caenorhabditis elegans spermatogenesis factor fer-1 is mutated in limb girdle muscular dystrophy type 2B. Nat Genet 1998;20:37-42.

[5] Liu J, Aoki M, Illa I, et al. Dysferlin, a novel skeletal muscle gene, is mutated in Miyoshi myopathy and limb girdle muscular dystrophy. Nat Genet 1998;20:31-6.

[6] Roberds SL, Leturcq F, Allamand V, et al. Missense mutations in the adhalin gene linked to autosomal recessive muscular dystrophy. Cell 1994;8:625-33.

[7] Bönnemann CG, Modi R, Noguchi S, et al. Beta sarcoglycan (A3b) mutations cause autosomal recessive muscular dystrophy with loss of the sarcoglycan complex. Nat Genet 1995;11:266-73.
[8] Lim LE, Duclos F, Broux O, et al. Beta sarcoglycan (43DAG): characterization and role in limb girdle muscular dystrophy linked to chromosome 4q12. Nat Genet 1995;11:257-65.

[9] Noguchi S, McNally EM, Othmane KB, et al. Mutations in the dystrophin-associated protein $\gamma$-sarcoglycan in chromosome 13 muscular dystrophy. Science 1995;270:819-22.

[10] Nigro V, Moreira ES, Piluso G, et al. Autosomal recessive limb girdle muscular dystrophy, LGMD2F, is caused by a mutation in the $\delta$ sarcoglycan gene. Nat Genet 1996;14:195-8.

[11] Moreira ES, Wiltshire TJ, Faulkner G, et al. Limb girdle muscular dystrophy type $2 \mathrm{G}$ is caused by mutations in the gene encoding the sarcomeric protein telethonin. Nat Genet 2000;24:163-6.

[12] Frosk P, Weiler T, Nylen E, et al. Limb girdle muscular dystrophy type $2 \mathrm{H}$ associated with mutation in TRIM32, a putative E3-ubiqutinligase gene. Am J Hum Genet 2002;70:663-72.

[13] Hackman P, Vihola A, Haravuori H, et al. Tibial muscular dystrophy is a titinopathy caused by mutations in TTN, the gene encoding the giant skeletal-muscle protein Titin. Am J Hum Genet 2002;71: 492-500.

[14] Brockington M, Blake D, Prandini P, et al. Mutations in the fukutinrelated protein gene (FKRP) cause a form of congenital muscular dystrophy with secondary laminin $\alpha 2$ deficiency and abnormal glycosylation of $\alpha$-dystroglycan. Am J Hum Genet 2001;69:1198-209.

[15] Brockington M, Yuva Y, Prandini P, et al. Mutations in the fukutin related protein gene (FKRP) identify Limb girdle muscular dystrophy 2I as a milder allelic variant of congenital muscular dystrophy MDC1C. Hum Mol Genet 2001;10:2851-9.

[16] Ibraghimov-Beskrovnaya O, Ervasti JM, Leveille CJ, Slaughter CA, Sernett SW, Campbell KP. Primary structure of dystrophin-associated glycoproteins linking dystrophin to the extracellular matrix. Nature 1992;355:696-702.

[17] Gesemann M, Cavalli V, Denzer AJ, Brancaccio A, Schumacher B, Ruegg MA. Alternative splicing of agrin alters its binding to heparin, dystroglycan, and the putative agrin receptor. Neuron 1996;16: 755-67.

[18] Chiba A, Matsumura K, Yamada H, et al. Structures of sialylated Olinked oligosaccarides of bovine peripheral nerve $\alpha$-dystroglycan. The role of a novel O-mannosyl-type oligosaccharide in the binding of $\alpha$ dystroglycan with laminin. J Biol Chem 1997;272:2156-62.

[19] Peng HB, Dagget DF, Rauvala H, Hassel JR, Smalheiser NR. The relationship between perlecan and dystroglycan and its implication in the formation of the neuromuscular junction. Cell Adhes Commun 1998;5:475-9.

[20] Bowe MA, Mendis DB, Fallon JR. The small leucine-rich repeat proteoglycan biglycan binds to alpha-dystroglycan and is upregulated in dystrophic muscle. J Cell Biol 2000;48:801-10.

[21] Michele DE, Barresi R, Kanagawa M, et al. Post translational disruption of dystroglycan-ligand interactions in congenital muscular dystrophies. Nature 2002;418:417-21.

[22] Holt KH, Crosbie RH, Venzke DP, Campbell KP. Biosynthesis of dystroglycan: processing of a precursor propeptide. FEBS Lett 2000; 468:79-83.

[23] Salih MA, Sunada Y, Al-Nasser M, et al. Muscular dystrophy associated with beta-dystroglycan deficiency. Ann Neurol 1996;40:925-8.

[24] Hayashi YK, Ogawa M, Tagawa K, et al. Selective deficiency of alpha-dystroglycan in Fukuyama-type congenital muscular dystrophy. Neurology 2001;57:115-21.

[25] Kano H, Kobayashi K, Herrmann R, et al. Deficiency of alphadystroglycan in muscle-eye-brain disease. Biochem Biophys Res Commun 2002;291:1283-6.

[26] Beltrán-Valero de Bernabé D, Currier A, Steinbrecher A, et al. Mutations in the O-mannosyltransferase gene POMT1 give rise to the severe neuronal migration disorder Walker-Warburg syndrome. Am J Hum Genet 2002;71:1033-43.

[27] Dincer P, Leturcq F, Richard I, et al. A biochemical, genetic and clinical survey of autosomal recessive limb girdle muscular dystrophies in Turkey. Ann Neurol 1997;42:222-9. 
[28] Dincer P, Akçören Z, Demir E, et al. A cross section of autosomal recessive limb girdle muscular dystrophies in 38 families. J Med Genet 2000;37:361-7.

[29] Hillaire D, Helbling-Leclerc A, Faure S, et al. Localization of merosin negative congenital muscular dystrophy to chromosome $6 \mathrm{q} 2$ by homozygosity mapping. Hum Mol Genet 1994;3:1657-61.

[30] Helbling-Leclerc A, Topaloglu H, Tomer FM, et al. Readjusting the localization of merosin (laminin alpha 2-chain) deficient congenital muscular dystrophy locus on chromosome 6q2. C R Acad Sci III 1995;318:1245-52.

[31] Naom IS, D'Alessandro M, Topaloglu H, et al. Refinement of the laminin alpha2 chain locus to human chromosome $6 \mathrm{q} 2$ in severe and mild merosin deficient congenital muscular dystrophy. J Med Genet 1997;34:99-104.

[32] Moghadaszadeh B, Desguerre I, Topaloglu H, et al. Identification of a new locus for a peculiar form of congenital muscular dystrophy with early rigidity of the spine, on chromosome 1p35-36. Am J Hum Genet 1998;62:1439-45.

[33] Cormand B, Avela K, Pihko H, et al. Assignment of the muscle-eyebrain disease gene to $1 \mathrm{p} 32-\mathrm{p} 34$ by linkage analysis and homozygosity mapping. Am J Hum Genet 1999;64:126-35.

[34] Toda T, Segawa M, Nomura Y, et al. Localization of a gene for Fukuyama type congenital muscular dystrophy to chromosome 9q3133. Nat Genet 1993;5:283-6.

[35] Dib C, Faure S, Fizames C, et al. A comprehensive genetic map of the human genome based on 5264 microsatellites. Nature 1996;380:152-4.
[36] Piccolo F, Roberds SL, Jeanpierre M, et al. Primary adhalinopathy: a common cause of autosomal recessive muscular dystrophy of variable severity. Nat Genet 1995;10:243-5.

[37] Kessler SW. Use of protein A-bearing staphylococci for the immunoprecipitation and isolation of antigens from cells. Methods Enzymol 1981;73:442-59.

[38] Herrmann R, Straub V, Blank M, et al. Dissociation of the dystroglycan complex in caveolin-3-deficient limb girdle muscular dystrophy. Hum Mol Genet 2000;9:2335-40.

[39] Winder SJ. The complexity of dystroglycan. Trends Biochem Sci 2001;26:118-24.

[40] Muntoni F, Brockington M, Torelli S, Blake D, Brown S. Defective glycosylation in muscular dystrophy. Lancet 2002;360: 1419-21.

[41] Kobayashi K, Nakahori Y, Miyake M, et al. An ancient retrotransposal insertion causes Fukuyama-type congenital muscular dystrophy. Nature 1998;394:388-92.

[42] Zaccaria ML, Di Tommasa F, Brancaccio A, Paggi P, Petrucci TC. Dystroglycan distribution in adult mouse brain: a light and electron microscopic study. Neuroscience 2001;104:311-24.

[43] Moore SA, Salto F, Chen J, et al. Deletion of brain dystroglycan recapitulates aspects of congenital muscular dystrophy. Nature 2002 ; 418:422-5.

[44] Sugita S, Saito F, Tang J, Satz J, Campbell K, Südhof TC. A stoichiometric complex of neurexins and dystroglycan in brain. J Cell Biol 2001;154:435-45. 